\title{
Food insecurity and food pantry use among transgender and gender non- conforming people in the Southeast United States
}

\author{
Jennifer Russomanno ${ }^{*}$ and Jennifer M. Jabson Tree
}

\begin{abstract}
Background: Transgender and gender non-conforming (TGNC) people face high rates of poverty, joblessness, and homelessness, rendering this population vulnerable to experiencing food insecurity. Yet, there is almost no empirical evidence concerning food insecurity and the use of local and federal food assistance resources in the TGNC community. Food insecurity, the use of local and Federal food assistance resources, and associations with gender-related minority stressors and resilience using the Gender Minority Stress and Resilience (GMSR) scale among TGNC individuals living in the Southeast United States (U.S.) were documented in this study.

Methods: A cross-sectional online survey was conducted with TGNC people living in the Southeast U.S. Participants were recruited via targeted Facebook advertisements.

Results: In total, 105 TGNC people completed the survey; 79\% of survey participants experienced food insecurity, 19\% utilized Federal, and 22\% utilized local food assistance resources. High levels of minority stress and community resilience were reported. The GMSR resilience scale Pride (aOR $=1.09,95 \% \mathrm{Cl} 1.00-1.19, p=.04$ ) was significantly associated with the use of local food pantries, but minority stressors were not. No significant associations were found between GMSR and food security.

Conclusion: TGNC people living in the Southeast U.S. experienced food insecurity, unstable housing, low wages, and social stigma that were a barrier to using emergency food resources. Multi-level public health solutions that address discriminatory legislative policies and create linkages between TGNC people and local and federal food assistance are required to address issues of food insecurity in the TGNC population.
\end{abstract}

Keywords: Transgender, Food insecurity, Health disparities, Food pantries, LGBTQ

\section{Background}

In the United States (U.S.), 1 in 9 people (11.1\%) is food insecure [1]. Food security is defined as access by all people at all times to enough food for an active, healthy life and, at minimum, includes the availability of nutritionally adequate and safe foods, and the assured ability

\footnotetext{
* Correspondence: jrussoma@utk.edu

The University of Tennessee Department of Public Health, 1924 Alcoa Highway, Knoxville, TN 37920, USA
}

to acquire food in a socially acceptable way [2]. People who are able to meet these standards on a daily basis are considered food secure, and those that cannot are considered food insecure [2]. Federal organizations name food insecurity as a pressing public health challenge that contributes to hunger, obesity, chronic disease, and poor overall health [3-6].

Food insecurity disproportionately affects certain groups of people, including those living in poverty,

(c) The Author(s). 2020 Open Access This article is licensed under a Creative Commons Attribution 4.0 International License, which permits use, sharing, adaptation, distribution and reproduction in any medium or format, as long as you give appropriate credit to the original author(s) and the source, provide a link to the Creative Commons licence, and indicate if changes were made. The images or other third party material in this article are included in the article's Creative Commons licence, unless indicated otherwise in a credit line to the material. If material is not included in the article's Creative Commons licence and your intended use is not permitted by statutory regulation or exceeds the permitted use, you will need to obtain permission directly from the copyright holder. To view a copy of this licence, visit http://creativecommons.org/licenses/by/4.0/ The Creative Commons Public Domain Dedication waiver (http://creativecommons.org/publicdomain/zero/1.0/) applies to the data made available in this article, unless otherwise stated in a credit line to the data. 
people who are under or unemployed, and the homeless $[3,6,7]$. Transgender and gender non-conforming (TGNC) people (individuals whose gender identity is different from their sex assigned at birth) are a diverse group of people who experience some of the highest risks for food insecurity. Based on the 2015 U.S. Transgender Survey (USTS), [8] TGNC people are 4 times more likely to have incomes below $\$ 10,000$ /year, are 3 times more likely to be unemployed, and 2.5 times more likely to experience homelessness in their lifetimes, compared to cisgender (gender identity is concurrent with sex assigned at birth) counterparts [8].

TGNC people also face the burden of minority stressors in the form of discrimination, stigma, and marginalization as a result of their gender identities. Minority stress is a chronic, cumulative, and institutional source of stress built into how organizations and societies function and exists beyond the control of the individual or subgroup that it targets [9]. Minority stress affects TGNC people's internal perceptions of themselves, their relationships with peers, family members and community members, their integration and acceptance into community groups, clubs or religious institutions, and their rights as dictated by governmental laws and legislation [9-11].

Although TGNC people are exposed to minority stressors, this group is also resilient. Meyer [10] referred to this resilience as community resilience, or minority coping. Community resilience is a sense that individuals can overcome life challenges and obstacles with the assistance of close community networks and support. For TGNC people with strong community or social support, community resilience may be protective against minority stress [10]. Multi-level minority stressors and community resilience may contribute to or protect against the negative consequences of food insecurity in the TGNC population, however, these associations have not yet been empirically explored and documented.

Where a person lives also influences their experiences with and risk for food insecurity, minority stress, and community resilience. TGNC people living in states with high rates of food insecurity and sociopolitical contexts that produce discrimination and stigma, may be at especially high risk for food insecurity. Of the 12 Southeast states (Alabama, Arkansas, Florida, Georgia, Kentucky, Louisiana, Mississippi, North Carolina, South Carolina, Tennessee, Virginia, West Virginia), 9 have food insecurity rates above the national average [12]. Additionally, the Southeast states, have, on average, very high levels of social stigma toward Lesbian, Gay, Bisexual \& Transgender (LGBT) people, [11] evidenced by the absence of employment or non-discrimination laws that protect this population [11]. High levels of social stigma combined with non-protective laws decrease the safety, economic stability, and acceptance of the estimated 380, 000 TGNC people living in the Southeast U.S. [11, 13]

In the general population, local food assistance programs, such as food pantries, are valuable resources to alleviate food insecurity [14]. A majority of U.S. food pantries (67\%) are run by faith-based institutions, [15] which could pose a great threat to food insecure TGNC people. State Religious Freedom Restoration Acts (RFRA), or "religious freedom laws" allow institutions, including food pantries, to deny services to select community members based on religious beliefs [16]. These laws allow food pantries to deny TGNC people support and thereby further jeopardize food access to this population [17].

\section{Study purpose}

The purpose of this study was two-fold. First, we aimed to describe TGNC peoples' experiences with food insecurity, including their use of Federal and local food assistance resources. Second, we sought to investigate possible associations between gender-related minority stressors and community resilience and the experience of food insecurity and use of local food assistance resources among TGNC people in the Southeast U.S.

\section{Methods}

The University of Tennessee Institutional Review Board approved all study procedures (UTK IRB-18-04907-XP).

\section{Pilot test}

To ensure survey quality and that questions were appropriate and sensitive to the priority population, the survey was pilot tested with a person who self-identified as transgender male, and who resided in Tennessee. The pilot tester provided positive feedback about the survey questions and did not suggest modifications to the survey protocol. The survey was not modified after the pilot test, prior to public dissemination.

\section{Recruitment}

From January to February 2019, TGNC people living in the Southeast U.S. were recruited online via targeted Facebook advertisements to complete an online survey. This recruitment approach is an evidence-based method documented to successfully recruit stigmatized groups into research projects [18-21].

\section{Eligibility}

Eligibility was determined with a 4-item online eligibility questionnaire. Determining eligibility required potential survey participants to: (1) agree to participate via informed consent, (2) live in 1 of the 12 Southeast U.S. states, (3) be over age 18, and (4) self-identify as TGNC. Responses were required for each item before it was 
possible to advance to the full survey instrument. Upon clicking on the survey link embedded in the Facebook advertisement, potential respondents were directed to an online informed consent form with response options of "agree to participate" or "decline to participate." Respondents who selected "decline to participate" were considered ineligible to participate, and were directed to the end of the survey, thanking them for their time. Respondents who selected "agree to participate" were directed to the remaining items on the eligibility questionnaire.

Survey participation was voluntary and confidential. Participants could voluntarily provide a name and email address to be entered to win 1 of 4 randomly-selected $\$ 50$ electronic gift cards. Names and email addresses were not associated with survey responses.

\section{Participation}

Seven hundred and forty-two people clicked the survey link. Of those, 166 (22.4\%) consented to participate. Nineteen participants (11.4\%) either did not meet eligibility criteria $(n=16)$ or left the survey prior to the first question of the full survey $(n=3)$.

\section{Measures}

The cross-sectional survey was conducted online via Qualtrics and measured: (1) food insecurity; (2) use of local and Federal food assistance resources; (3) genderrelated stress and resilience; and (4) demographic characteristics. All "prefer not to answer" responses to any survey item were coded as missing.

\section{Food insecurity}

Food insecurity was assessed using the USDA 6-item Short Form Food Security Module [22]. This measure identifies food insecure households [22] with Cronbach's alpha $(\alpha)$ ranging from 0.74 to 0.93 [23]. USDArecommended scoring guidelines [2] were used to calculate participant food security scores. Overall scores were summed, with a total possible score of 0-6. Final participant scores were dichotomized: food secure (raw score $0-1$ ) and food insecure (raw score 2-6) [22].

\section{Local and federal food assistance programs}

Two survey items were used to assess participants' experiences with the Federal Supplemental Nutrition Assistance Program (SNAP), and 6 items assessed participants' experiences with local food pantries (Table 1). These items were designed by the research team specifically for this survey. Skip progressions were used for questions regarding federal food assistance and use of local food assistance programs. Regarding Federal food assistance, all participants were asked whether they had received SNAP benefits in the past 12 months. If a participant indicated they had received benefits during this period, they were directed to an additional follow-up question assessing their average monthly SNAP allowance. Regarding local food assistance programs, all participants were asked whether they had use local food assistance programs in the past 12 months. If a participant indicated they were not currently using food pantries, they were directed to a follow-up question regarding why they currently did not utilize these resources. All participants were asked the remaining 4 questions regarding local food assistance resources capturing organizing agencies of their local pantries and assessing the welcoming nature of pantries to TGNC people.

\section{Gender-related stress and resilience}

Gender-related stress and resilience were assessed using the Gender Minority Stress and Resilience (GMSR) scale [24]. The Cronbach's alphas reported in previous studies using the GMSR scale ranged from 0.61 (gender-related discrimination) to 0.93 (negative expectations for the future) [24, 25]. GMSR scoring guidelines [24] were used to calculate participant scores within each subscale. Higher scores indicated a higher minority stress and/or resilience depending on subscale.

\section{Demographics}

Demographic variables included: state of residence, gender identity, [26] age, [27] geographic location (urban, suburban, rural), marital status, [27] race, [27] ethnicity, [27] education, [27] employment status, [27] household income, [27] housing stability, [28] and number of children in the household [27].

\section{Statistical analyses}

Food insecurity and local and federal food assistance

Summary statistics were calculated for food insecurity and receipt of SNAP benefits and use of local food pantries. Open-ended questions concerning experiences with local food assistance resources were analyzed qualitatively by categorizing and sorting the responses into overarching themes.

\section{Gender-related minority stress}

Mean GMSR subscale scores were calculated.

\section{Demographics}

Frequencies and percentages for all demographic variables were calculated.

\section{Associations between GMSR and food insecurity/local and federal food assistance}

Logistic regression models were calculated with adjustment for demographic characteristics, to test for associations between GMSR subscales and (1) food pantry usage and (2) food security. All adjustment variables 
Table 1 Local and Federal food assistance program survey questions

Question
1. Do you currently, or have you in the past 12 months, received assistance through
the Supplemental Nutrition Assistance Program (SNAP) (formerly known as food
stamps)?
[all participants]

2. On average, how much in SNAP assistance did/do you receive monthly? [participants who responded Yes in Q1]

3. Do you currently, or have you in the past 12 months, use local food assistance programs such as food pantries?

[all participants]

4. Why do you not currently use local food pantries? (select all that apply) [participants who responded no current food pantry use in Q3]

5. Who is the organizer of your local food pantry? (if more than one pantry exists in your community, select all that apply)

[all participants]

6. Overall, how welcoming do you feel your local food pantry is to transgender or gender non-conforming people?

[all participants]

7. In your own words, please describe how your local food pantry is welcoming to transgender or gender non-conforming people. [all participants]

8. In your own words, please describe how your local food pantry is unwelcoming to Open ended transgender or gender non-conforming people. [all participants]

were selected based on associations in bivariate analyses. Per published guidelines [29], variables that were significant at $<0.15$ in the bivariate analyses were included as adjustment variables in the multivariable regression
Potential Responses

1. Yes, I/We currently receive SNAP assistance

2. Yes, I/We have received SNAP assistance in the past 12 months, but do not currently receive assistance

3. No, I/We have not received SNAP assistance in the past 12 months

4. Prefer not to answer

1. Less than $\$ 50$

2. $\$ 50-\$ 99$

3. $\$ 100-\$ 149$

4. $\$ 150-\$ 199$

5. $\$ 200$ or more

1. Yes, I/We currently use them

2. Yes, I/We have used them in the past 12 months, but do not currently

3. No, I/We do not use them and have not used them in the past 12 months

4. Prefer not to answer

1. I do not need to use these resources at this time

2. I do not feel these resources are meant for me

3. I do not feel comfortable using these resources

4. I do not have transportation to these resources

5. I do not feel welcome at these resources

6. I did not know these resources existed

7. None of these resources are available to me in my community

8. Other, please describe

9. Prefer not to answer

1. Church or faith-based organization

2. Charitable, non-profit organization (such as Second Harvest)

3. A local college or university

4. I am not aware of any food pantries in my community

5. I do not know who organizes my local food pantry

6. Prefer not to answer

1. Extremely welcoming

2. Somewhat welcoming

3. Neither welcoming nor unwelcoming

4. Somewhat unwelcoming

5. Extremely unwelcoming

Open ended models. The six regression models calculated were: (1) food pantry usage regressed on the 7 full-sample GMSR subscales; ( $2 \& 3)$ food pantry usage regressed on the 2 partial-sample GMSR subscales (negative expectations 
for the future and nondisclosure) for the "gender history" and "gender identity" participant subgroups; (4) food security regressed on the 7 full-sample GMSR subscales; and ( $5 \& 6$ ) food security regressed on the 2 partialsample GMSR subscales for the "gender history" and "gender identity" participant subgroups.

Logistic regression models testing the associations between GMSR and food security and use of food pantries were calculated as nested models, with demographic covariates included in Block 1, and GMSR subscales in Block 2.

\section{Missing data}

As recommended [30, 31], respondents were excluded from analyses if they were missing more than $20 \%$ of survey items. In our tests of missingness according to recommended guidelines [31, 32], there were no obvious patterns of missingness within excluded cases $X^{2}$ (18, $N=147)$ 17.11, $p=.52$. Therefore, cases were considered missing completely at random (MCAR). According to Peng [31], MCAR assumes the "probability of a response depends on neither the observed nor the missing value that could have been collected or recorded" among cases with $20 \%$ missing data. Under conditions where data are MCAR, complete removal of cases with $20 \%$ or more missing data will not produce biased estimates to the remaining data [31]. For this project, 42 MCAR cases were excluded, leaving 105 cases in the final analyses.

Respondents who were missing fewer than $20 \%$ of survey items had item-level missing data handled by multiple imputation (MI) or mean substitution based on the percent of data missing [30, 31, 33]. In the remaining 105 cases, there were varying levels of missing data at the item level ranging from $17.1 \%$ (food security) to $0 \%$ (state of residence; geographic location; number of children in household). Given the level of missingness in food security (17.1\%), MI was conducted. The rate of missing information in the food security variable did not exceed $50 \%$, therefore, based on published guidelines, 5 imputations were used in the MI model $[34,35]$. The predictive variables used to impute food security in the model were receipt of SNAP benefits and use of local food pantries. These two variables were chosen as predictor variables based on their association with food insecurity in the general population $[14,36]$. For variables with low level missing data $(<4 \%)$, mean substitution was utilized [33]. Previous studies suggest that mean substitution is comparable to more complex methods at when low levels of missingness are present $[31,33]$. All analyses were conducted using IBM SPSS Statistics Version 25 [37].

\section{Sample size and power analysis}

Post hoc power analyses were calculated [38] using the GMSR scale and applying the widest $95 \% \mathrm{CI}$ and widest standard deviation (95\% CI: $13.8-17.2$; sd $=8.81$ ). The statistical analysis had $80 \%$ power to detect associations if was associations were present $(n=105)$.

\section{Results \\ Participants}

Within our study sample, we had at least one participant from each of the 12 Southeastern U.S. states. Most participants were White (85.7\%), non-Hispanic (94.3\%), employed or self-employed (68.6\%), and had at least some college education (80\%). Of the participants that did not identify as White $(n=15), 6.7 \%(n=7)$ identified as mixed race, $3.8 \%(n=4)$ identified as Black or African American, 1.9\% $(n=2)$ identified as "other," $1 \%(n=1)$ identified as American Indian, and 1\% $(n=1)$ identified as Asian. The mean age of our study sample was 27.4 years $(s d=8.6)$. Participants identified across a range of gender identities; the majority identified as non-binary $(40 \%)$, transgender male (30.5\%), and/or genderqueer (26.7\%) (Fig. 1).

\section{Food insecurity}

Table 2 contains a summary of the pooled results of differences in food security and food pantry by sample demographic characteristics. Food insecurity was identified among $79 \%$ of participants $(n=83)$. Among those who were food insecure, $20 \%(n=17)$ reported low food security, and $80 \%(n=66)$ reported very low food security. The remaining $21 \%$ of participants $(n=22)$ were food secure. Among those who were food secure, $68.2 \%$ $(n=15)$ reported high food security and $31.8 \%(n=7)$ reported marginal food security.

\section{Food assistance resources}

The majority of participants reported never receiving SNAP benefits $(n=85,81 \%)$ and never using local food pantries $(n=78,74.3 \%)$. Participants reported not using food pantries for multiple reasons, ranging from feeling like food pantries were not meant for them $(n=43,41 \%)$ to not having adequate transportation $(n=12,11.4 \%)$. Participants reported a variety of food pantry organizers, including faith-based organizations $(n=53,50.5 \%)$, nonprofit organizations $(n=29,27.6 \%)$ and local colleges $(n=9,8.6 \%)$.

Participants reported feeling unwelcome at local food pantries due to their TGNC status, particularly at pantries operated by faith-based organizations (Table 3). One participant stated, "People are required to sit through a church service, and the pastor has spoken against homosexuality, which made me uncomfortable." Another recalled, "It is Christian based and that tends not to go well for us here." Participants also suggested that food pantries may be unwelcoming due to the socio-conservative climate of the Southeast U.S. One 


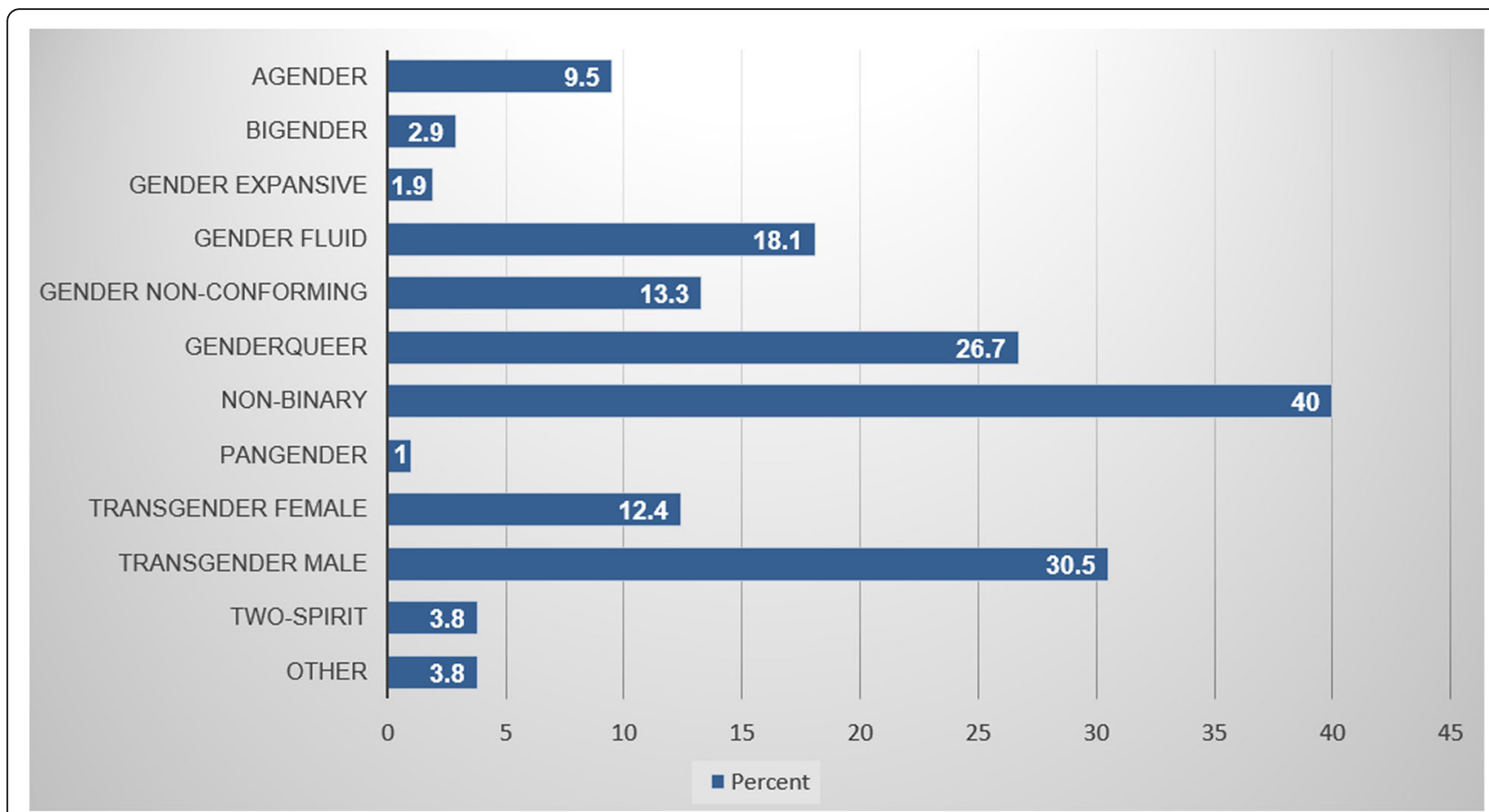

Fig. 1 Survey participant gender identities

participant stated, "I'm in the Bible Belt, they say we do not exist or are mentally challenged."

\section{Gender-related minority stressors and community resilience}

Table 4 provides a summary of participants' mean GMSR scores, including alphas from our sample. The highest reported scores were gender-related rejection $(\mathrm{M}=4.07, \mathrm{sd}=1.48)$ and non-affirmation of gender identity $(\mathrm{M}=18.83, \mathrm{sd}=5.77)$. In response to the question, "Do you currently live in your affirmed gender all or almost all of the time," 74 participants (70.5\%) stated they lived in their affirmed gender all or almost all of the time and were presented with the terminology of "gender history" in the subscales of negative expectations for the future and nondisclosure. Thirty-one participants (29.5\%) stated they did not live in their affirmed gender all or almost all of the time and were presented with the terminology of "gender identity" in the aforementioned subscales.

\section{Associations between GMSR, food pantry usage, and food security}

Food pantry usage was regressed on the GMSR subscales, with adjustment for receipt of SNAP benefits (Table 5). There was a positive association between the Pride subscale and the use of food pantries $(\mathrm{aOR}=1.09$, 95\% CI 1.00-1.19, $p=.04$ ). Participants who were more self-assured in their gender identity were $9 \%$ more likely to use food pantries than those who were less-assured. No significant associations were found between any GMSR subscales and food security (see Supplemental Table 1).

\section{Discussion}

In this study, we set out to document: (1) food insecurity experiences had by TGNC individuals living in the Southeast U.S., (2) the experiences had by TGNC people when utilizing Federal and local food assistance resources, and (3) how gender-related minority stressors and community resilience relate to food insecurity and the use of local food assistance resources.

A majority of survey participants experienced food insecurity $(n=83 ; 79 \%)$, and few participants utilized Federal $(n=20,19 \%)$ and local $(n=27,25.7 \%)$ food assistance resources. Participants had high levels of minority stress and community resilience. Minority stressors were not related to food insecurity or the use of local food pantries. However, community resilience was associated with local food pantry usage.

There is very little evidence about food insecurity in the TGNC population, and there are several gaps in what is known. The existing literature combines experiences of food insecurity among TGNC people with people who identify as gay, lesbian, and bisexual. This makes it impossible to understand the unique experiences of TGNC people. Additionally, the existing evidence does not use a rigorous measurement for food 
Table 2 Food security status and food pantry usage by demographic characteristics $(n=105)$

\begin{tabular}{|c|c|c|c|c|c|c|c|c|c|c|c|c|c|c|}
\hline & \multirow[t]{2}{*}{$\begin{array}{c}\text { Total } \\
\mathbf{N} \\
105 \\
\end{array}$} & \multirow[t]{2}{*}{$\begin{array}{c}\text { Total } \\
\%\end{array}$} & \multicolumn{2}{|c|}{$\begin{array}{l}\text { Food } \\
\text { Secure } \\
(\mathrm{n}=22)\end{array}$} & \multicolumn{2}{|c|}{$\begin{array}{l}\text { Food } \\
\text { Insecure } \\
(\mathrm{n}=83)\end{array}$} & \multirow[b]{2}{*}{$\mathrm{X} 2$} & \multirow[b]{2}{*}{$\mathrm{p}$} & \multicolumn{2}{|c|}{$\begin{array}{l}\text { Food Pantry } \\
\text { "Ever User" } \\
(\mathrm{n}=27)\end{array}$} & \multicolumn{2}{|c|}{$\begin{array}{l}\text { Food Pantry } \\
\text { "Never User" } \\
(\mathrm{n}=78)\end{array}$} & \multirow[b]{2}{*}{$\mathrm{X} 2$} & \multirow[b]{2}{*}{$\mathrm{p}$} \\
\hline & & & $\mathrm{N}$ & $\%$ & $\mathrm{~N}$ & $\%$ & & & $\mathrm{~N}$ & $\%$ & $\mathrm{~N}$ & $\%$ & & \\
\hline Age & & & & & & & 9.77 & 0.04 & & & & & 2.97 & 0.56 \\
\hline $18-24$ & 52 & 49.1 & 5 & 22.7 & 47 & 56.7 & & & 14 & 51.9 & 38 & 48.7 & & \\
\hline $25-34$ & 38 & 36.5 & 11 & 50.0 & 27 & 32.5 & & & 7 & 25.9 & 31 & 39.7 & & \\
\hline 35 or older & 15 & 14.4 & 6 & 27.3 & 9 & 10.8 & & & 6 & 22.2 & 9 & 11.6 & & \\
\hline Education & & & & & & & 8.89 & 0.03 & & & & & 0.63 & 0.89 \\
\hline HS Diploma/GED or less & 21 & 20.0 & 2 & 9.0 & 19 & 22.9 & & & 6 & 22.3 & 15 & 19.3 & & \\
\hline Some college & 50 & 47.6 & 6 & 27.3 & 44 & 53.0 & & & 13 & 48.1 & 37 & 47.4 & & \\
\hline College graduate & 34 & 32.4 & 14 & 63.7 & 20 & 24.1 & & & 8 & 29.6 & 26 & 33.3 & & \\
\hline \# of Children in Hous ehold & & & & & & & 8.62 & 0.07 & & & & & 2.88 & 0.58 \\
\hline 0 & 81 & 77.1 & 16 & 72.8 & 65 & 78.4 & & & 19 & 70.4 & 62 & 79.5 & & \\
\hline 1 or more & 24 & 22.9 & 6 & 27.2 & 8 & 21.6 & & & 8 & 29.6 & 16 & 20.5 & & \\
\hline Race & & & & & & & 0.17 & 0.68 & & & & & 0.30 & 0.58 \\
\hline White & 90 & 85.7 & 18 & 81.8 & 72 & 86.7 & & & 24 & 88.9 & 66 & 84.6 & & \\
\hline Non-White & 15 & 14.3 & 4 & 18.2 & 11 & 13.3 & & & 3 & 11.1 & 12 & 15.4 & & \\
\hline Ethnicity & & & & & & & 0.01 & 0.92 & & & & & 0.18 & 0.67 \\
\hline Hispanic & 6 & 5.7 & 1 & 4.5 & 5 & 6.0 & & & 2 & 7.4 & 4 & 5.2 & & \\
\hline Non-Hispanic & 99 & 94.3 & 21 & 95.5 & 78 & 94.0 & & & 25 & 92.6 & 74 & 94.8 & & \\
\hline Stable Housing & & & & & & & 3.27 & 0.07 & & & & & 1.32 & 0.25 \\
\hline Yes & 92 & 87.6 & 22 & 100.0 & 70 & 84.3 & & & 21 & 77.8 & 71 & 91.0 & & \\
\hline No & 13 & 12.4 & 0 & 0.0 & 13 & 15.7 & & & 6 & 22.2 & 7 & 9.0 & & \\
\hline Employment & & & & & & & 2.05 & 0.15 & & & & & 2.85 & 0.91 \\
\hline Employed or self-employed & 72 & 68.6 & 18 & 82.0 & 54 & 65.0 & & & 15 & 55.6 & 57 & 73.1 & & \\
\hline Not currently employed for wages & 33 & 31.4 & 4 & 18.0 & 29 & 35.0 & & & 12 & 44.4 & 21 & 26.9 & & \\
\hline SNAP Status & & & & & & & 3.27 & 0.19 & & & & & 4.81 & 0.08 \\
\hline Ever Received SNAP & 20 & 19.0 & 0 & 0.0 & 20 & 24.0 & & & 9 & 33.3 & 11 & 14.1 & & \\
\hline Never Received SNAP & 85 & 81.0 & 22 & 100.0 & 63 & 76.0 & & & 18 & 66.7 & 67 & 85.9 & & \\
\hline Marital Status & & & & & & & 6.33 & 0.04 & & & & & 0.39 & 0.82 \\
\hline Single & 17 & 16.2 & 7 & 31.8 & 10 & 12.0 & & & 5 & 18.50 & 12 & 15.4 & & \\
\hline Married & 37 & 35.2 & 9 & 41.0 & 28 & 33.7 & & & 8 & 29.60 & 28 & 35.90 & & \\
\hline Member of an unmarried couple & 51 & 48.6 & 6 & 27.2 & 45 & 54.3 & & & 14 & 51.90 & 38 & 48.70 & & \\
\hline Geographic Location & & & & & & & 0.47 & 0.79 & & & & & 0.88 & 0.64 \\
\hline Urban & 38 & 36.2 & 8 & 36.4 & 30 & 36.1 & & & 11 & 40.7 & 27 & 34.60 & & \\
\hline Suburban & 45 & 42.8 & 7 & 31.8 & 38 & 45.8 & & & 12 & 44.40 & 33 & 42.30 & & \\
\hline Rural & 22 & 21.0 & 7 & 31.8 & 15 & 18.1 & & & 4 & 14.80 & 18 & 23.10 & & \\
\hline
\end{tabular}

insecurity. For example, Brown and colleagues [39] found that $27 \%$ of LGBT adults experienced a time in the last year when they did not have enough money to feed themselves or their families. However, two methodological issues [39] limit what can be understood from Brown and colleagues about food insecurity in the TGNC population. First, only one of the four data sources used by Brown's study assessed transgender inclusive gender identity, and gender identity and sexual orientation questions were combined in a single identity measure [39]. This is problematic because it is impossible to determine how many of the food insecure participants reported by Brown and colleagues identify as transgender, and therefore the proportion of TGNC people who experience food insecurity.

Second, the TGNC-inclusive data source in Brown and colleagues' project used only a single-item to assess food security [39]. A single measure does not accurately assess the dynamic complexities and factors of food insecurity, made up of multiple factors including: access to food, whether food supplies are regular and consistent, and whether available food is healthy and filling [39]. We used the USDA approved 6-item assessment of food security in order to more fully inform the dynamic experience of food insecurity among TGNC people. 
Table 3 Open-ended comments regarding the welcoming nature of food pantries

In your own words, please describe how your local food pantry is welcoming to transgender or gender non-conforming people.

- They are very welcoming. Just very nice to everyone.

- I believe it's more of a "what they don't know won't hurt them" situation; if they don't know that I/someone am/is trans or gendernon-conforming, then there isn't a problem.

- I imagine the one at the college I work at is much more welcoming than the religious pantry located nearest me.

- It is run by my college, which is accepting to the LGBT community.

- They did not care either way or didn't notice.

- We don't know; my girlfriend and I are both pre-op and stealth (I present female and she presents male in public).

- Food Not Bombs is very welcoming

- Second Harvest is supported by the UU church, and they support TGNC people.

- The food pantry is at my local church (ORUUC) but offers this to anyone in need in the local community. I felt welcoming and like they treated me like they would anyone else that came to them for assistance.

In your own words, please describe how your local food pantry is unwelcoming to transgender or gender non-conforming people.

- Everybody stares, whispers of "what is that", "she's just confused"

- We aren't the normal racist "Christians" that seem to be the majority here

- Hateful angry passive aggressive or just aggressive. Refusing prejudice and making remarks towards the community Spectrum. Often times I met with threats of violence or hateful looks and am treated unfairly among places like the food pantry or food stamp office to a point to where paperwork has been manipulated, dodged, thrown away, or edited

-We are surrounded by hate and transphobes

- People are required to sit through a church service, and the pastor has spoken against homosexuality, which made me uncomfortable.

- Tells us we are going to hell or there's only two genders and go seek medical assistant

- Transgender people not allowed

- The area I live in is very bigoted, and the community harbors hate for lgbtqia folks.

- I'm in the Bible Belt, they say we do not exist or are mentally challenged

- It is Christian based and that tends not to go well for us here.

- Tennessee resents people like us. That's fact.

- It's in a church and not one of the ones I know tends to be lgbt friendly

- FISH pantries may be staffed by trans/homophobic volunteers

- I haven't experienced being unwelcome at my local food pantry but I feel unwelcome by most religious based organizations and many organizations in general in this area unless I know they're LGBTQ friendly and welcoming.

It is possible that the rates of food insecurity for TGNC people are likely to be much higher than what we identified with our project. From an economic perspective, our study produced findings similar to those published from the 2011 U.S. National Transgender Discrimination Survey (NTDS). The NTDS described structural, economic, and health challenges faced by transgender people in the U.S. For example, 14\% of Southeast U.S. NTDS respondents had yearly incomes under $\$ 10,000$, and $14 \%$ experienced unstable housing in the past year due to their gender identity/expression [40]. In our study, $19 \%$ of survey respondents reported yearly incomes of less than $\$ 10,000$, and $12.7 \%$ experienced unstable housing within the past 2 years. Future studies should consider how under and unemployment as well as household instability are associated with food insecurity among the TGNC population, primarily in regions of the U.S. that do not have anti-discrimination housing or employment policies in place.

In their study assessing health outcomes of LGBT people in various regions of the U.S., Hasenbush and colleagues [11], found that a high percentage of LGBT people living in states without anti-discrimination protection laws had at least some college education. They concluded that LGBT people living in states without legislative protections (including all of the Southeast U.S. states) may seek advanced education to bolster their employment prospects in response to workplace discrimination that might be encountered in these areas [11].

Participants in our study may be similar to those who participated in the Hasenbush study. Despite low annual incomes reported by survey respondents, a majority (79.6\%) had some higher level education. Of those that reported having at least some college education, $41.5 \%$ were college graduates. This is consonant with hypotheses that marginalized people living in states with high levels of social stigma seek higher educational attainment in an effort to combat potential discrimination in workplace settings.

Previous studies suggest that TGNC people experience high levels of harassment [41], employment discrimination [42], and community discrimination $[42,43]$ due to their TGNC status. Bradford and colleagues [42] assessed gender-related discrimination among transgender people in Virginia and found that $41 \%$ reported experiencing gender-related discrimination in one or more of the following areas: health care, employment, and housing. Results from our study are similar. Above-the-mean scores were observed in 3 of the GMSR subscales assessing minority stress and social stigma: gender-related discrimination, gender-related rejection and non-affirmation of gender identity, indicating that survey respondents were experiencing high levels of social stigma, rejection, and discrimination in their communities.

Results from our study indicated that personal pride in one's TGNC identity was associated with greater likelihood of using local food pantries. It is possible that personal pride could be protective against 
Table 4 Gender minority stress and resilience (GMSR) measure summary statistics

\begin{tabular}{|c|c|c|c|c|c|}
\hline Subscale & $\mathrm{N}$ & Min & Max & Mean $(s d)$ & a \\
\hline Gender-related discrimination & 105 & 0 & 5 & $2.77(1.45)$ & .60 \\
\hline Gender-related rejection & 105 & 0 & 6 & $4.07(1.48)$ & .55 \\
\hline Gender-related victimization & 105 & 0 & 6 & $2.54(1.93)$ & .79 \\
\hline Non-affirmation of gender identity & 105 & 0 & 24 & $18.83(5.77)$ & .90 \\
\hline Internalized transphobia & 105 & 0 & 32 & $15.51(8.81)$ & .90 \\
\hline Pride & 105 & 0 & 32 & $18.48(7.85)$ & .88 \\
\hline Negative Expectations for the future (Gender history) & 74 & 0 & 36 & $23.29(8.06)$ & .89 \\
\hline Negative Expectations for the future (Gender identity) & 31 & 0 & 36 & $28.57(5.92)$ & .86 \\
\hline Nondisclosure (Gender history) & 74 & 0 & 20 & $12.13(6.25)$ & .88 \\
\hline Nondisclosure (Gender identity) & 31 & 0 & 20 & $12.87(5.43)$ & .83 \\
\hline Community connectedness & 105 & 0 & 20 & $12.19(4.94)$ & .83 \\
\hline
\end{tabular}

minority stress and social stigma. In their qualitative study of transgender people of color residing in the Southeast U.S., Singh and McKleroy [44] found that participants with a higher sense of pride were better able to overcome barriers of transphobia and racism within their communities than those with a lower sense of pride. It is possible that TGNC people who are proud of their gender identity may be better equipped to overcome potential issues of discrimination or transphobia when securing food from local food pantries than those who may feel less proud of their gender identity.

\section{Limitations}

This study has limitations. Participants were purposively recruited via convenience sampling through targeted

Table 5 Binary logistic regression predicting likelihood of food pantry usage by full-sample GMSR subscale scores, when adjusting for SNAP status $X^{2}(8,105)=13.13 p=.11$

\begin{tabular}{lllll}
\hline & aOR & $95.0 \%$ & C.I. & $p$ \\
\hline $\begin{array}{l}\text { Block } 1 \\
\text { SNAP status }\end{array}$ & LL & UP & \\
& & & & 0.03
\end{tabular}

Never received SNAP

ref

Ever received SNAP

Block 2

GMSR Subscales (full sample)

\begin{tabular}{lllll} 
Gender-related discrimination & 0.87 & 0.55 & 1.38 & 0.56 \\
Gender-related rejection & 0.81 & 0.52 & 1.26 & 0.35 \\
Gender-related victimization & 1.23 & 0.84 & 1.80 & 0.30 \\
Non-affirmation of gender identity & 0.98 & 0.88 & 1.08 & 0.65 \\
Internalized transphobia & 0.99 & 0.92 & 1.06 & 0.75 \\
Pride & 1.09 & 1.00 & 1.19 & $\mathbf{0 . 0 4}$ \\
Community & 0.91 & 0.81 & 1.02 & 0.10 \\
nant & 2.06 & & & 0.63 \\
\hline
\end{tabular}

Facebook advertisements. Additionally, a vast majority of survey participants were white, non-Hispanic. Thus, our results cannot be generalized past our sample's demographic characteristics.

In total, 742 people clicked on the Facebook advertisement, but only 166 people actually consented to participate and moved forward to the eligibility screening. No data were collected from potential participants prior to consenting to the project, therefore it is not possible to determine why 166 of the 742 consented to participate and others did not. It is conceivable that individuals were initially curious about the project, but realized that they were not eligible, or were not interested in participation. It is possible, although not testable, that individuals who consented to participate are different in important ways from those who did consent to participation, and this limits the generalizability of this study.

\section{Conclusions}

Several interrelated, multi-level, public health solutions are required to alleviate issues of food insecurity and food access in the TGNC population. Federally, national population-based surveys assessing food security in the general population should be required to capture gender identity so public health professionals can use the most rigorous epidemiological methods to accurately assess food insecurity within the TGNC population. Currently none of the health surveillance programs include TGNC inclusive measures of gender [45]. Structurally, Federal or State level legislation must be established to protect TGNC people from social stigma and discrimination in employment, housing, and healthcare. Federally, and within the Southeast U.S. states, laws do not guard against discrimination for TGNC individuals [11, 46]. RFRA laws actively allow institutions and employers to deny services and opportunities to TGNC people based on religious beliefs. Lack of legal protection and discriminatory laws jeopardize TGNC peoples' employment 
opportunities, housing options, food security, and access to community food resources. Future research should consider exploring food insecurity and food assistance use by TGNC people on a national level, allowing for comparisons of TGNC people residing in states with and without anti-discrimination policies in place.

Given the majority of survey participants were food insecure, yet very few sought help from local food assistance resources, several community-wide solutions could also be implemented to ensure food insecure TGNC people have safe, affirming resources for food. One possible solution is for TGNC community organizations to partner with local food pantries to ensure a nonthreatening, welcoming environment is being created for TGNC people in need of food assistance. In addition, local food pantries and TGNC community organizations could work together to provide "pop-up" food pantries in places that are easily accessible to TGNC people in need.

\section{Supplementary information}

Supplementary information accompanies this paper at https://doi.org/10. 1186/s12889-020-08684-8.

Additional file 1: Table S1. Binary logistic regression predicting likelihood of food insecurity by full-sample GMSR subscale scores, when adjusting for age, education, children, housing stability, and marital status $X^{2}(8,105)=33.04 p=.005$

\section{Abbreviations}

GMSR: Gender Minority Stress and Resilience Scale; LGBT: Lesbian, Gay, Bisexual \& Transgender; NTDS: 2011 National Transgender Discrimination Survey; RFRA: Religious Freedom Restoration Acts; SNAP: Supplemental Nutrition Assistance Program; TGNC: Transgender and Gender Nonconforming; U.S.: United States; USDA: United States Department of Agriculture; USTS: 2015 U.S. Transgender Survey

\section{Acknowledgements}

None

\section{Authors' contributions}

$J R$ proposed the research idea, created the needs assessment, conducted a literature review, designed and distributed the survey, analyzed the data, and wrote the initial draft of the manuscript. JJT assisted in the design and distribution of the survey, data analysis, and was a major contributor in writing and editing the manuscript. Given that JR was a doctoral candidate at the time of the study, JJT approved the study process in its entirety. The author(s) read and approved the final manuscript.

\section{Funding}

None.

\section{Availability of data and materials}

The datasets used and/or analyzed during the study are available from the corresponding author on reasonable request.

\section{Ethics approval}

The University of Tennessee Institutional Review Board approved all study procedures (UTK IRB-18-04907-XP). Written consent was obtained from all survey participants.

\section{Consent for publication}

Not applicable.

\section{Competing interests}

The authors declare that they have no competing interests.

Received: 8 October 2019 Accepted: 8 April 2020

Published online: 29 April 2020

\section{References}

1. United States Department of Agriculture. Food security in the US 2019 Available from: https://www.ers.usda.gov/topics/food-nutrition-assistance/ food-security-in-the-us/interactive-charts-and-highlights/.

2. United States Department of Agriculture. Definitions of food security 2014 Available from: http://www.ers.usda.gov/topics/food-nutrition-assistance/ food-security-in-the-us/definitions-of-food-security.aspx.

3. United States Department of Agriculture. Food security status of U.S. households in 20162017 Available from: https://www.ers.usda.gov/topics/ food-nutrition-assistance/food-security-in-the-us/key-statistics-graphics.aspx.

4. Gregory CA, Coleman-Jensen A. Food insecurity, chronic disease, and health among working-age adults: United States Department of Agriculture, Economic Research Service; 2017.

5. Office of Disease Prevention and Health Promotion. Healthy people 2020: food insecurity 2019 Available from: https://www.healthypeople.gov/2020/ topics-objectives/topic/social-determinants-health/interventions-resources/ food-insecurity.

6. Seligman HK, Laraia BA, Kushel MB. Food insecurity is associated with chronic disease among low-income NHANES participants. J Nutr. 2010; 140(2):304-10.

7. The United States Conference of Mayors. The U.S. Conference of Mayors' Report on Hunger and Homelessness. 2016.

8. James SE, Herman JL, Rankin S, Keisling M, Mottet L, Anafi M. The report of the 2015 U.S. transgender survey. Washington: National Center for Transgender Equality; 2016.

9. Meyer $\mathbb{I H}$. Minority stress and mental health in gay men. J Health Soc Behav. 1995;36(1):38-56.

10. Meyer $\mathbb{H}$. Resilience in the study of minority stress and health of sexual and gender minorities. Psychol Sex Orientat Gend Divers. 2015;2(3):209.

11. Hasenbush A, Flores A, Kastanis A, Sears B, Gates G. The LGBT divide: a data portrait of LGBT people in the Midwestern, Mountain \& Southern states; 2014

12. United States Department of Agriculture. Food security in the United States: how do States compare? 2017 Available from: https://www.ers.usda.gov/ topics/food-nutrition-assistance/food-security-in-the-us/interactive-chartsand-highlights/.

13. Flores A, Herman J, Gates G, Brown T. How many adults identify as transgender in the United States? Los Angeles: The Williams Institute 2016. Authors provide a contemporary estimate of the prevalance of transgender individuals in the US; 2017.

14. Bhattarai GR, Duffy PA, Raymond J. Use of food pantries and food stamps in low-income households in the United States. J Consum Aff. 2005:39(2):27698.

15. Briefel RR, Jacobson J, Tiehen L. The emergency food assistance system: findings from the client survey. Washington: US Department of Agriculture, Economic Research Service; 2003.

16. National Conference of State Legislatures. 2017 Religious Freedom Restoration Act Legislation 2017 Available from: http://www.ncsl.org/ research/civil-and-criminal-justice/2017-religious-freedom-restoration-actlegislation.aspx.

17. Hunger Free America. Pride highlights work left to be done for LGBT food access 2017 Available from: https://www.hungerfreeamerica.org/blog/pridehighlights-work-left-be-done-lgbt-food-access\#_ftn3.

18. Russomanno J, Patterson J, Jabson J. Food security and transgender and gender non-conforming individuals in the Southeast United States: a qualitative study. Transgender Health. 2019;4(1):1-11.

19. Mitchell J, Lee J-Y, Stephenson R. How best to obtain valid, verifiable data online from male couples? Lessons learned from an eHealth HIV prevention intervention for HIV-negative male couples. JMIR Public Health Surveillance. 2016;2(2):e152-e.

20. Carter-Harris L. Facebook targeted advertisement for research recruitment: a primer for nurse researchers. Appl Nurs Res. 2016;32:144-7.

21. Russomanno J, Patterson JG, Tree JM. Social Media Recruitment of Marginalized, Hard-to-Reach Populations: Development of Recruitment and 
Monitoring Guidelines. JMIR Public Health and Surveillance. 2019;5(4): e14886.

22. United States Department of Agriculture. Survey Tools 2017 Available from: https://www.ers.usda.gov/topics/food-nutrition-assistance/food-security-inthe-us/survey-tools/.

23. Keenan DP, Olson C, Hersey JC, Parmer SM. Measures of food insecurity/ security. J Nutr Educ. 2001;33:S49-58.

24. Testa RJ, Habarth J, Peta J, Balsam K, Bockting W. Development of the gender minority stress and resilience measure. Psychol Sex Orientat Gend Divers. 2015;2(1):65.

25. Gliem JA, Gliem RR. Calculating, interpreting, and reporting Cronbach's alpha reliability coefficient for Likert-type scales. Midwest Research-toPractice Conference in Adult, Continuing, and Community Education. https://scholarworks.iupui.edu/bitstream/handle/1805/344/Gliem\%20\%26\%2 OGliem.pdf? sequence $=1$ \&isAllowed $=y$.

26. Trans Student Educational Resources. LGBTQ+ Definitions 2018 Available from: http://www.transstudent.org/definitions.

27. Centers for Disease Control and Prevention. Behavioral risk factor surveillance system survey questionnaire. Atlanta, Georgia: U.S. Department of Health and Human Services, Centers for Disease Control and Prevention; 2018.

28. United States Interagency Council on Homelessness. Sample housing and homelessness status assessment questions 2017 Available from: https:// www.usich.gov/resources/uploads/asset_library/CE_Sample_Housing_ Status_Questions.pdf.

29. Bursac Z Gauss CH, Williams DK, Hosmer DW. Purposeful selection of variables in logistic regression. Source Code Biol Med. 2008;3(1):17.

30. Acock AC. Working with missing values. J Marriage Fam. 2005;67(4):1012-28.

31. Peng C-YJ, Harwell M, Liou S-M, Ehman LH. Advances in missing data methods and implications for educational researc, Chapter 3. In: Sawilowsky SS, editor. Real data analysis. New York: 2006. p. 31-78.

32. Li C. Little's test of missing completely at random. Stata J. 2013;13(4):795-809.

33. Parent MC. Handling item-level missing data: simpler is just as good. Couns Psychol. 2013;41(4):568-600.

34. Schafer JL. Multiple imputation: a primer. Stat Methods Med Res. 1999:8(1): 3-15.

35. Rubin DB. Multiple imputation for nonresponse in surveys: John Wiley \& Sons; 2004.

36. Daponte BO, Lewis GH, Sanders S, Taylor L. Food pantry use among lowincome households in Allegheny County, Pennsylvania. J Nutr Educ. 1998; 30(1):50-7.

37. Corp IBM. IBM SPSS statistics for windows, version 25.0. Armonk: IBM Corp; 2017.

38. UCSF. Sample size calculators 2019 Available from: http://www.sample-size. net/sample-size-conf-interval-mean/.

39. Brown TN, Romero AP, Gates GJ. Food insecurity and SNAP participation in the LGBT community; 2016.

40. James SE, Herman JL, Rankin S, Keisling M, Mottet L, Anafi M. National Transgender Discrimination Survey: southern states results. Washington: National Center for Transgender Equality; 2011.

41. Beemyn G, Rankin S. The lives of transgender people: Columbia University press; 2011.

42. Bradford J, Reisner SL, Honnold JA, Xavier J. Experiences of transgenderrelated discrimination and implications for health: results from the Virginia transgender health initiative study. Am J Public Health. 2013;103(10):1820-9.

43. Factor RJ, Rothblum ED. A study of transgender adults and their nontransgender siblings on demographic characteristics, social support, and experiences of violence. J LGBT Health Res. 2007;3(3):11-30.

44. Singh AA, McKleroy VS. "Just getting out of bed is a revolutionary act" the resilience of transgender people of color who have survived traumatic life events. Traumatology. 2011;17(2):34-44.

45. Patterson JG, Jabson JM, Bowen DJ. Measuring sexual and gender minority populations in health surveillance. LGBT health. 2017:4(2):82-105.

46. Movement Advancement Project. Policy \& issue analysis 2018 Available from: http://www.lgbtmap.org/policy-and-issue-analysis.

\section{Publisher's Note}

Springer Nature remains neutral with regard to jurisdictional claims in published maps and institutional affiliations.

Ready to submit your research? Choose BMC and benefit from:

- fast, convenient online submission

- thorough peer review by experienced researchers in your field

- rapid publication on acceptance

- support for research data, including large and complex data types

- gold Open Access which fosters wider collaboration and increased citations

- maximum visibility for your research: over $100 \mathrm{M}$ website views per year

At $\mathrm{BMC}$, research is always in progress.

Learn more biomedcentral.com/submissions 